\title{
DOM PREDAKA U ISLAMU GRČKOM KAO PJESNIČKI MOTIV. JEDNA NEPOZNATA PJESMA NA TALIJANSKOM JEZIKU IZ ARHIVA OBITELJI DESNICA
}

\section{Sanja Roić}

UDK: 821.163.42-1Desnica, V.“1931“(=131.1)

Izvorni znanstveni članak

Sažetak: Od vremena mletačke uprave na prostoru Dalmacije prepleću se elementi hrvatske, srpske i talijanske kulture i civilizacije. Talijanski jezik i talijanska kultura imanentni su ne samo etničkim Talijanima koji žive na tom prostoru, nego i obrazovanim Slavenima. Interkulturne odnose valja sagledavati u tom svjetlu sve do konca Drugog svjetskog rata, kad većina Talijana napušta Dalmaciju i Istru. No, kulturna prepletanja ostala su prisutna za trajanja života pojedinaca talijanske narodnosti koji su na tom prostoru ostali i nakon rata, kao i u znanstvenim i stručnim radovima te istraživanjima hrvatskih i srpskih povjesničara, talijanista i komparatista. U tom kontekstu analiziram do sada nepoznati dokument iz arhiva obitelji Desnica, datiran 1931. godine, i atribuiram ga Vladanu Desnici, intelektualcu i potonjem književniku koji je na najvišoj umjetničkoj razini u nas sintetizirao poticaje tih triju kultura u svojoj književnoj praksi i u svom intelektualnom djelovanju.

Ključne riječi: hrvatsko-srpsko-talijanska kulturna prepletanja u Dalmaciji, nepoznata pjesma na talijanskom jeziku, opus Vladana Desnice, opus Uroša Desnice

I.

5 enaslovljenu pjesmu napisanu na talijanskom jeziku pronašao je u arhivu obitelji Desnica profesor Drago Roksandić. Zahvaljujem mu na povjerenju i mogućnosti da je analiziram u ovom radu. U prvom smo času i profesor Roksandić i ja pretpostavili da se radi o autorskom tekstu pravnika i publicista dr. Uroša Desnice upućenom sinu Vladanu, tada dvadesetšestogodišnjaku. Sačuvana je i omotnica u kojoj je 57-godišnji advokat pošiljku poslao poštom iz Splita u Zagreb 21. prosinca 1931. ${ }^{1}$ Na omotnici je vidljiv i žig pošiljateljeva odvjetničkog ureda.

1 Pošiljatelj: „Dr. Uroš Desnica / Advokat / Sinjska ulica br. 7 / Telefon Interurban br. 3-41“. Primatelj: „G. Vladan Desnica / Zagreb / Konvikt Bl. Kvirina / Trvtkova 5“. Poštanski pečat: „Zagreb / Загреб / D / A /21 XII $3110 “ . ~ N a$ 
Poznato je da je Uroš Desnica nakon Prvog svjetskog rata bio interniran u Italiji, no zatim se sklonio najprije na imanje u Islamu Grčkom, a kasnije u Obrovac, gdje je ostao do kraja rata. Ponukan političkim događajima u vezi s pripojenjem Zadra Italiji, pisao je na talijanskom jeziku „Lettere dal Zermagna“ ('Pisma sa Zrmanje') upućena Zadraninu Nataleu Krekichu. ${ }^{2}$ Tih šest članaka u formi epistola izašlo je u zadarskom dvojezičnom $\mathrm{Na}$ rodnom listu (Il Nazionale) u razdoblju od 25. veljače 1919. do 29. travnja 1920. U prvom pismu Desnica stariji piše: „Dragi Nade! Osamljen u svome skloništu na obalama Zrmanje već pet godina pratim slijed događaja koji potresaju svijet; udaljen od gradske buke i nadmetanja, pratim ih okom nepristranog i objektivnog promatrača. ${ }^{\text {"3 }}$ Odrastao u Dalmaciji, bečki student i diplomirani pravnik, potom interniran u umbrijski gradić Gualdo Tadino, ${ }^{4}$ Uroš Desnica nije samo razumijevao i čitao, nego je i pisao stihove na zadarskom dijalektu i prozu na talijanskom jeziku. Nekoliko dokumenata iz obiteljskog arhiva svjedoči i da je $s$ toga jezika i prevodio.

Ti su argumenti činjenica da je otac bio pošiljatelj pisma s pjesmom. Sadržaj i forma pjesme koji navode na pomisao da je njezin autor zrela osoba, a ne mladić u prvi su mah govorili u prilog tezi da je njen autor Uroš Desnica. No, nakon pomnog čitanja i analize, ipak mislim da je autor pjesme na talijanskom jeziku zapravo Urošev sin - u vrijeme kad je poslana diplomirani pravnik, mladi intelektualac, ali ne još i književnik - Vladan Desnica. Otac je stihove pročitao, redigirao na nekoliko mjesta svojom rukom i zatim poštom uputio sinu, koji je, nakon što je 1927./1928. godine boravio na studiju u Parizu, nastavio i završio 1930. započeti studij prava na Sveučilištu u Zagrebu. Prema biografskim podacima, od 1. srpnja 1930. do 30. kolovoza 1932. radio je kao pripravnik u očevoj advokatskoj kancelariji u Splitu. U prosincu 1931., ne znamo iz kojih razloga, zatekao se u Zagrebu. Osim toga, taj pjesnički sastavak Vladan ne navodi u očevoj bibliografiji radova na talijan-

žigu kružnog oblika stoji: „Dr Uroš Desnica / u Splitu / Advokat“. Osvrt na književnu, prevodilačku (s talijanskog i njemačkog jezika) i publicističku ostavštinu Uroša Desnice (Obrovac, 1874. - Split, 1941.) još nije načinjen.

2 Natale Krekich (Skradin, 1857. - Zadar, 1938.) diplomirao je pravo u Grazu, a zatim bio odvjetnik u Zadru. Uroš Desnica obraća mu se prisno s „moj Nade“ (mio Nade). Pristalica Dalmatinske autonomističke stranke koja se gorljivo borila za talijanski Zadar, Krekich je kasnije, 1924., pristupio talijanskoj Fašističkoj partiji, a 1933. imenovan je senatorom Kraljevine Italije. Danas jedna ulica na južnoj periferiji Rima nosi njegovo ime.

3 „Caro Nade! Solitario nel mio ritiro sulle sponde del Zermagna, seguo da cinque anni l'avvicendarsi degli avvenimenti che perturbano il mondo e, lontano dal fragore e dalle competizioni della città, li seguo con occhio di osservatore spassionato e imparziale“. Hrvatski prijevod moj, S. R. Ukupno šest „Pisama sa Zrmanje“, Narodni list (Il Nazionale) (Zadar), br. 8, 25. 2. 1919., 1; br. 9, 27. 2. 1919., 1; br. 13, 28. 3. 1919., 2; br. 11, 14. 3. 1919., 2-3; br. 23, 7. 6. 1919., 2; br. 2, 29. 4. 1920., 2. Uroš Desnica potpisao se talijanskim pseudonimom Nemesio (hrv. Nemesije), aludirajući na grčkog filozofskog pisca, biskupa u Emesi, današnjem Homsu u Siriji, koji je u spisu O čovjekovoj prirodi nastojao uskladiti grčku antropologiju i kršćansku dogmu. Usp. Leksikon antičkih autora (prir. Dubravko Śkiljan), Zagreb 1996., 430. I Obrovac i Homs smješteni su na obalama iznimnih rijeka; Obrovac je na Zrmanji, pa su odatle i „Pisma sa Zrmanje“. Talijanskom hidronimu Zermagna trebao bi, zbog početnog suglasnika, prethoditi član lo, ortografsko pravilo koje autor previđa i u drugim kontekstima.

$4 \mathrm{Na}$ stranici http://www.gualdograndeguerra.com/index.php/prigionieri-e-internati-a-gualdo-tadino nalaze se podaci o tome da su neposredno nakon završetka Prvog svjetskog rata stotine Dalmatinaca s područja koje je okupirala talijanska vojska bili internirani u Italiju zbog „nepatriotskih osjećaja“. Tako su 22 zatočenika „iz Šibenika“ (misli se na šibenski kraj) bila internirana u Gualdo Tadino, u to vrijeme gradić s oko 12.000 stanovnika, kamo su dospjeli nakon osam dana napornog puta. Među njima bili su i Uroš i Boito [sic!] Boško Desnica. U bilješci se, uz fotografiju interniraca, navodi da su oni bili odvjetnici, nastavnici, političari, svećenici, da su dobivali naknadu za prisilni rad od 2 lire dnevno, isto koliko i građani Gualdo Tadina koji su ih primili na smještaj u svoje kuće, te „da su nakon povratka u domovinu 1923. Nikola Novaković i Uroš Desnica izabrani kao zastupnici iz šibenskog kraja u Hrvatski sabor". 
skom jeziku. ${ }^{5}$ Premda je Vladan još mladić, atmosfera pjesme bliska je njegovu misaonom svijetu; on je sâm isticao da je roman Proljeća Ivana Galeba pisao i smišljao čitavih dvadeset pet godina. ${ }^{6}$ Uroš Desnica je na talijanskom napisao jednu gramatiku ruskog jezika, socijalno i politički angažirane novinske članke, recenzije i burleskne stihove. Premda je sin tvrdio da je otac bolji stilist od njega, potonji je bio vrlo samokritičan: „Tražit ću ispriku kod čitatelja s druge obale zbog svoga šepavog talijanskog, no oni su sigurno već primijetili da je talijanski kojim se govori i piše ovdje kod nas biljka bez korijena, slična mladici ruže nakalemljenoj na hrastov panj"?

$S$ druge strane, imamo i potvrde da je Vladan Desnica mogući autor pjesme na talijanskom jeziku. U tekstu „Dva susreta s Vladanom Desnicom“ Dimitrije Mašanović piše: „Mogao je, reče mi, da piše na italijanskom jeziku, jer ga je dobro poznavao, a nastojao je da što više čita u originalu. “8 Odrastao u dvojezičnom Zadru i dalmatinskim gradovima Splitu i Šibeniku, ali obrazovan na materinskom jeziku, Vladan Desnica više je puta boravio u Italiji i odlično poznavao talijanski jezik, znao je umetati talijanske riječi i izraze u svoju prozu. ${ }^{9}$ Talijanu Erosu Sequiju, predavaču i kasnije profesoru na zagrebačkoj i beogradskoj Talijanistici, Desnica je već koncem 1952. ili početkom 1953. poslao početne stranice svog, kako ga je nazvao, „lirskog romančića“, zapravo Proljeća Ivana Galeba, sa sugestijama kako prevesti pojedine riječi i izraze na talijanski, i tom prigodom dodao da mu rad na prijevodu neće biti težak, ,jer su materija i izražajni načini i forme takvi da se kudikamo lakše i prirodnije daju izraziti na talijanskome nego na našem jeziku, što sam obilno iskusio pri pisanju“. ${ }^{10}$ Sequi je 1957. i preveo LV. i LVI. poglavlje Proljeća, a 1958. mu je Desnica opet pisao o prevođenju svog romana, koji je bio „mišljen i stilski oblikovan više u načinu romanskih jezika nego slavenskih, tako da bi bila kao neka 'ritraduzione's prevoda na original“", ${ }^{11}$ pa tako eksplicitno iznosi moduse svoje poetike i ključno mjesto talijanske kulture u njoj.

5 Usp. Prilog $\mathrm{C}$ u ovom radu. Zahvaljujem profesoru Roksandiću na ustupljenom popisu.

6 Vladan Desnica, Hotimično iskustvo, knj. 2., Zagreb 2006., 121.

7 Nemesio [Uroš Desnica], „Lettere dal Zermagna“, Narodni list (Zadar), br. 23, 7. 6. 1919., 2: „Chiederò scusa ai lettori d'oltremare del mio italiano claudicante, ma essi devono già aver notato, che l'italiano che si parla e si scrive qui da noi è una pianta senza radici e rassomiglia a un virgulto di rosa mal innestato su un ceppo di quercia“. Prijevod na hrvatski moj, S. R. Isti navod u vlastitom prijevodu prenosi i Kosta Milutinović, „Od Stojana Jankovića do Vladana Desnice“, Zadarska revija, 18/1968., 1, 31.

8 Usp. V. Desnica, Hotimično iskustvo, 109. Tekst je objavljen kao svojevrsni In memoriam, neposredno nakon piščeve smrti 18. ožujka 1967. u beogradskim Književnim novinama, 19/1967., br. 297, 1 i 12. Dodajem da je Vladan Desnica preveo na talijanski Posvetu iz Njegoševe Luče mikrokozme, za što imamo potvrdu u njegovoj prepisci s Erosom Sequijem, profesorom Beogradskog univerziteta i urednikom riječkog časopisa La battana. Taj je prijevod, nažalost, zagubljen. Usp. Željko Đurić, Srpsko-italijanske književne i kulturne veze od XVIII do XX veka, Beograd 2012. 798-801.

9 O opravdanoj kritici nekih drugih pisaca koji su to nevješto pokušavali usp. Desničin rad „Književna kozmetika“, u: Hotimično iskustvo, 202-204.

10 Ž. Đurić, Srpsko-italijanske književne i kulturne veze, 793. Ako je Desnica, kako je sâm posvjedočio, na Proljećima radio punih 25 godina, onda se početak rada može locirati već u 1928., godinu boravka u Parizu. Bit će zanimljivo usporediti početne stranice romana poslane Sequiju s verzijom tiskanom u sarajevskom časopisu Život 1954.

11 Ritraduzione u značenju 'prijevod prijevoda'. Pisma su citirana u: Ž. Đurić, Srpsko-italijanske književne i kulturne veze, 793. I u pismu britanskom slavistu Edwardu Goyju Desnica ističe da je neke dijelove romana mislio na talijanskom jeziku. Usp. Dušan Puvačıć, „Priča o izgubljenom rukopisu (Trideset šest pisama Vladana Desnice E. D. Goju“, Letopis Matice srpske, 172/1996., knj. 458, sv. 6, 329. 
Pretpostavljam da je ta svoja znanja i vještine pisac svjesno prešućivao sa sugovornicima koji nisu bili italofoni, zbog kontroverzi što su ih u poslijeratnoj intelektualnoj sredini izazivali njegova visoka kultura i obrazovanje. To bi moglo biti i moguće opravdanje zašto je, inače pedantni bibliograf koji je datirao i potpisivao svoje i tuđe rukopise, ovu pjesmu ostavio nesigniranom.

Dulji pjesnički sastavak, otisnut pisaćim strojem na dvjema stranicama, broji dvanaest katrena dvanaesteraca (ukupno 48 stihova) rimovanih prema konstantnoj shemi $a b c b$, bez istaknutog naslova, a napisan je na talijanskom jeziku visokog stilskog registra. Prema uzusu talijanske lirike Trecenta (14. stoljeća), sastavci nisu nosili naslove, pa se označavaju i citiraju početnim stihom, u ovom slučaju: Lento e misurato il rodere del tarlo (doslovan prijevod: 'Polagano i temeljito glodanje crva'). No, odakle „crv“ u takvoj pjesmi? ${ }^{12}$

U talijanskoj je poeziji crv (= tarlo) česta usporedba ili metafora za tajne, intimne patnje (u našoj je semantici, međutim, vezan za sumnju: crv sumnje, nemira, prevare). ${ }^{13}$ Leksem tarlo prisutan je i u Petrarkinoj i u Carduccijevoj poeziji. ${ }^{14}$ Stih dvanaesterac (podsjećam, talijanska je lirika pretežno pisana jedanaestercem) upućuje na autorovo poznavanje i prihvaćanje dubrovačke petrarkističke tradicije, specifičnog lokalnog petrarkizma jedinstvenog u svijetu koji se u formalnom aspektu oslanjao na tradiciju naše narodne, usmene lirike. Knjiga Petrarkinih Rasutih rima u jednom starom izdanju (Rime, Venezia 1776.) nalazila se u Desničinoj biblioteci u Zagrebu.

$S$ druge strane, katreni (opet, jedanaesteraca) karakteristični su za devetnaestostoljetnu poeziju Giosuea Carduccija, prvog talijanskog nobelovca (1906.), čije je pjesništvo imalo velikog odjeka u zemlji i inozemstvu, posebno u italofonim krajevima, kakva je bila Dalmacija sve do 1945. Poznato mi je i iz usmenih svjedočenja članova moje obitelji da su se Carduccijevi sastavci učili napamet u dalmatinskim školama gdje se taj jezik podučavao ili gdje se nastava održavala na talijanskom jeziku.

Zanimljivo je da se sintagma le ver irréfutable u dvostrukom značenju, prvom: 'nepobitni, neizbježni crv' i drugom: 'neizbježni stih', nalazi u XIX. strofi ${ }^{15}$ Valéryjeve poeme $L e$

$\overline{12}$ „Crv" se ne nalazi u Desničinu pojmovniku u knjizi Hotimično iskustvo, 319-398.

$13 \mathrm{Na}$ talijanskom se pojam crva vezuje za bol, grižnju savjesti, zavist i ljubomoru. Izraz ,averci il tarlo con qualcuno“ u doslovnom prijevodu glasi: 'imati crva spram nekog', u značenju 'ljutiti se na nekoga'.

14 Petrarca piše u Kanconijeru: Ei sa che 'l vero parlo: / ché legno vecchio mai non rose tarlo / come questi [Amore] 'l mio core, in che sannida, / et di morte lo sfida. RVF CCCLX, 68-71. U hrvatskom prijevodu Frane Cale: „On istinu zna: crva / ne bje što starog nagrizo se drva / ko on mog srca, gdje u gnijezdo leti, / i smrću njemu prijeti." U: Francesco Petrarca, Il Canzoniere / Kanconijer (ur. Frano Čale), Zagreb - Dubrovnik 1974., 911. Taj isti stih navodi Benedetto Croce u svom eseju o Petrarki.

Carducci: „Or freddo, assiduo, del pensiero il tarlo / Mi trafora il cervello, ond'io dolente / Misere cose scrivo e tristi parlo." Stihovi XL.-XLII. pjesme Idillio maremmano u: Giosue CARDuCCI, Rime nuove (1867., 1872.), u: Letteratura Italiana Einaudi, pretisak iz Edizione Nazionale delle Opere, Bologna 1942., 98.

15 XIX. strofa glasi: „Pères profonds, têtes inhabités, / Qui sous le poids de tant de pelletées, / Êtes la terre et confondes nos pas, / Le vrai rongeur, le ver irréfutable / N'est point pour vous qui dormez sous la table, / Il vit de vie, il ne me quitte pas!“. Neporecivi crv živi vlastitim životom, tijesno je povezan sa zmijom, za Valéryja simbolom savjesti. Prema jednoj od interpretacija, pjesničko 'ja' obraća se precima, a prema drugoj, velikim misliocima. Usp. dvojezično izdanje Paul Valéry, Il Cimitero marino (ur. Maria Teresa Giaveri), Milano 1984., 64-65, 121-122. 
cimetière marin ('Morsko groblje') dovršene 1920. godine, koju je Vladan Desnica, ako ne ranije, sigurno čitao za svoga boravka u Parizu nekoliko godina nakon toga.

Dva pridjeva koji se odnose na uporan rad crva, 'polagano' i 'uporno, temeljito', aludiraju na incipit glasovitog Petrarkina XXXV. soneta Solo et pensoso i più deserti campi / vo mesurando a passi tardi e lenti (u prijevodu: „Zamišljen, sâm, ja najpustije kraje / polaganim i sporim mjerim krokom "16), također introspektivnog i meditativnog karaktera. U zadnjoj Desničinoj strofi ovaj je pridjevski par modificiran u: „pigro e misurato“ ('lijen i uporan'), a pjesma i završava stihom koji sadrži četiri pridjeva: „gelido, imparziale, uniforme e lento“ ('leden, nepristran, jednoličan i polagan'), što ponovno svjedoči o privrženosti Petrarkinu stilu koji se potvrđuje pluralnostima, odnosno gomilanjem pridjeva, priloga, imenica koje karakteriziraju raspoloženje ili nakane pjesničkoga 'ja'.

U analiziranoj pjesmi pjesničko 'ja' prisutno je već u trećem stihu: „sento“ ('osjećam’), odmah uz sintagmu „,compier (...) l'opera di morte“, kako se dovršava destrukcija „,svete ruševine“ njegova doma. ${ }^{17}$ „Stari dom“, zazvan dvaput u vokativu: „O, mia vecchia casa“ i „o magione avita“18, simbol je povijesti obitelji; njezini su zidovi sada vlažni i pljesnivi, premda su joj svi u njoj rođeni za života dali obol. Dom predaka ima antropomorfna obilježja jer su se u njemu taložili djela, strepnje, tjeskobe, borbe i životne nevolje. Čuvar je, odnosno čuvarica, jer je riječ casa na talijanskom ženskog roda, stoljetne obiteljske povijesti, poput „krstionice“ (sacro fonte), ${ }^{19}$ čiji su potomci također hrabri i smjeli. Godišnja su doba poput ljudskog vijeka, a mladost koja snatri o vedroj budućnosti kao kratak je san. Na tom se mjestu intertekstualno priziva posljednji, XIV. stih Petrarkina prvog, uvodnog soneta u Kanconijer, Voi ch'ascoltate in rime sparse il suono ('Vi koji zvukom razasutih rima'): „che quanto piace al mondo è breve sogno" ('kratak je san na svijetu htijenje svako'). ${ }^{20}$

Ako je, kako pretpostavljam, mladi Vladan Desnica autor ove pjesme, moraju se zamijetiti njegovo izvrsno poznavanje talijanskog jezika visokog stilskog registra i umijeće stvaranja pjesničkih slika, oblika i metra po uzoru na talijansku liriku u različitim povijesnim razdobljima. Da je Vladan Desnica odlično poznavao početke talijanskog pjesništva i uspješno prevodio jednog od najkompleksnijih pjesnika toga doba, Danteova prijatelja Guida Cavalcantija, kao i samosvojnog, burlesknog Cecca Angiolierija, pokazala sam u radu „Vladan Desnica i pramaljeće talijanske lirike“. ${ }^{21} \mathrm{U}$ pjesničkom sastavku Lento e misurato

16 RVF XXXV. U hrvatskom prijevodu Mihovila Kombola, u: F. Petrarca, Il Canzoniere / Kanconijer, 103.

$17 \mathrm{U}$ originalu rijetki leksem magione, prema latinskom mansio, -onis, danas u uporabi samo kao književni pojam koji označava 'dom, stanište, ognjište'. Pridjev avita izveden je od avi (m., pl.), 'preci'.

18 Lento e misurato..., III. strofa, I. stih i V. strofa, II. stih. Moguća je i aluzija na Petrarkin sonet CCXXXIV O cameretta che già fosti un porto („O, sobice što nekoć bješe lukom“). U hrvatskom prijevodu Frane Čale, u: F. PETrarCA, Il Canzoniere / Kanconijer, 601.

19 Autor pokazuje da mu je poznato značenje 'krstionica' imenice fonte u muškom rodu u sintagmi sacro fonte jer ista imenica, ali ženskoga roda znači 'izvor'.

20 RVF I. U hrvatskom prijevodu Frane Čale, u: F. Petrarca, Il Canzoniere / Kanconijer, 8.

21 Usp. Sanja RoIć, Stranci. Portreti s granice, margine i periferije, Zagreb 2006., 144-157. 
il rodere del tarlo privrženost Petrarki očituje se i u primjeni retoričke figure sinalefe, vrlo česte u talijanskoj lirici, upravo zato što talijanski jezik obiluje vokalima na početku i kraju riječi, pa se slogovi mogu stapati.

Raspoloženje sastavka Lento e misurato il rodere del tarlo bilo bi primjerenije zrelom, starijem autoru, no poznato nam je da je Vladan Desnica tek 1934. objavio svoje prve radove i da je njegov odnos prema prošlosti, tradiciji, filozofiji života od samih početaka bio posve zreo. Mladi je Desnica živio između Splita, Šibenika, Zagreba te Islama Grčkog i Obrovca, putovao u Italiju i Francusku, a povijesni trenutak, početak 30-ih godina u tadašnjoj Jugoslaviji i svijetu, činio se pun obećanja, dok je istodobno nagovještavao avet fašizma, koja je u Italiji bila prisutna u svom aspektu Mussolinijeve takozvane „socijalne države“ već od 1921., a u Njemačkoj je dramatično započela 1933. godine.

Sin i otac razmjenjivali su tekstove; sin je čitao i poznavao očeve napise na talijanskom. U jednom od „Pisama sa Zrmanje“ iz 1919. Desnica stariji spominje poljanu sv. Šime u Zadru na kojoj se nalazi Krekichev dom predaka i označuje ga sintagmom magione avi$t a,{ }^{22}$ istom sintagmom koja se nalazi u petoj strofi, drugom stihu pjesme Lento e misurato il rodere del tarlo iz 1931. I pridjev imparziale iz posljednjeg stiha iste pjesme susreće se u jednom od „Pisama sa Zrmanje“. ${ }^{23}$

Moju tezu da se radi o strojopisnom autografu Vladana Desnice potkrepljuju i navodi i metrička obilježja iz drugih njegovih radova. Tako u romanu Proljeća Ivana Galeba dječak Ive ulazi u zaključanu odaju i na slici opaža nezavršen portret bakina brata čije ga oči gledaju tako prodorno kao da je čovjek upravo izveden iz samice: „Odnekud iza ugla - nisam mogao tačno odrediti pravca - čuo se marljivi rad crva. Malo poslije - ko bi ga znao zašto - on je prestao; imao sam osjećanje da nas neviđen posmatra. “" Spomenutog „crva“ iz originala u novom su talijanskom prijevodu Proljeća Ivana Galeba Giovanni Bensi i Luca Vaglio prenijeli upravo leksemom tarlo.

I u Desničinoj lirici mogu se pronaći neke od slika iz talijanske pjesme, na primjer u pjesmi Vidici, objavljenoj 1953.: „I mi se pognute glave vraćamo / u uze / naših memljivih ulica i kuća, / u tjeskobe / naših dana i naših noći..." ${ }^{25}$ Turobnija je atmosfera u pjesmi Kišobrani s podnaslovom „Ošamućeni građani u predvečerje drugog svjetskog rata“. Stihovi su kraći, osmerci i deveterci, ali je rima u katrenima $a b c b$, jednako kao u talijanskom sastavku, dosljedno provedena. ${ }^{26} \mathrm{U}$ pjesmi Čovjek strepi pod čeličnim pticama koje siju smrt zapisani su ovi stihovi: „Po ispucaloj hridi / bubica nepomućeno gmiže. / Samo čovjek, / sa svojim bijednim životom u kljunu, / poguren strepi: / zavidi drvetu, / zavidi bubici, / zavidi crvu u zemlji. ${ }^{27}$

\footnotetext{
22 Nemesio [Uroš Desnica], „Lettere dal Zermagna“, Narodni list (Zadar), br. 23., 7. 6. 1919., 2.

23 Usp. bilješku 3 u ovom radu.

24 V. Desnica, Proljeća Ivana Galeba. Igre proljeća i smrti, Zagreb 1975., 43. U novom talijanskom prijevodu: „In un angolo - non riuscivo a determinare chiaramente la direzione - si sentiva il lavoro diligente di un tarlo [istaknula $S$. R.]. Poco dopo, chissà perché, smise; avevo l'impressione che ci stesse spiando." Usp. V. Desnica, Le primavere di Ivan Galeb, Roma 2016., 58.

25 Vidici, pjesma objavljena 1953. pod naslovom Panika prostora, u: V. Desnica, Zimsko ljetovanje. Pjesme. Ljestve Jakovljeve, Zagreb 1974., 240.

26 Isto, 244.

27 Isto, 245.
} 
U članku „Zapisi o umjetnosti“, koji je 1952. objavljen u zagrebačkom časopisu Krugo$v i$, Desnica u jednom od primjera za „stilsku neurasteniju“ navodi slučaj nekog trgovca iz austrougarske provincije:

U toj je uličici stanovao postariji trgovac, žgoljav i, zato, kočoperan, koji se kasno naveče vraćao iz čitaonice s partije karata. Nije imao druge veze $s$ književnošću osim što je redovno čitao nastavke prevedenog romana Paul de Kocka u podlistku tršćanskog „Piccola“, ali mora da je imao stilskog crva u sebi. Nešto djelovanjem tog crva, a nešto valjda što je bio napržica i puntar, prve večeri naiđe uličicom, u potpunom mraku. ${ }^{28}$

U razgovoru s Jeftom Milovićem o umjetničkom stvaranju Vladan Desnica je još jednom spomenuo crva, ovoga puta „crva pisanja“: „Otac mi je bio čovjek velike kulture, ne samo opće nego i literarne specijalno, i vrlo istančanog ukusa i tako. U familiji se uopće to gajilo i čak četiri ili pet generacija unatrag ima tragova da su imali tog crva, toga crva pisanja, da tako kažem. ${ }^{\text {"29 }}$

\section{4 .}

U djelima Vladana Desnice, pa i kad su određena točnim vremenskim koordinatama, kao što je Zimsko ljetovanje, vlada atmosfera svevremenosti; njegov je realizam, kao što je to primijetio već Stanko Korać, realizam u detalju, u specifičnim malim slikama. Čovjek je u središtu njegove filozofije, ali, ne zaboravimo, čovjek kao „praunuk amebe“, biće koje pati, koje je zaokupljeno metafizikom. Čovjekova je svijest kadra promišljati onostrano, a utoliko je onostrano, prema Desnici, i relevantno. Ideja o patnji imanentnoj biću u pjesmi Lento e misurato il rodere del tarlo zapravo je ideja o prolaznosti, o prostoru (starom domu predaka), a cjelovita slika dobiva se sagledavanjem detalja. „Žalo“ Desničine Sjeverne Dalmacije, prostor isprepleten srpskom i hrvatskom kulturnom tradicijom, oduvijek je bilo izloženo romanskim, odnosno talijanskim kulturnim pobudama. Kultura istočne jadranske obale protkana je zlatnim nitima talijanske poezije Trecenta i Cinquecenta, još od starih Dubrovčana, Splićana i Hvarana, a moguće ih je razabrati i u nama vremenski mnogo bližem cjelovitom opusu Vladana Desnice.

No, s onu stranu pjesničkih slika, što je poznato o domu predaka, motivu pjesme? Radi se svakako o domu u Islamu Grčkom, kući i posjedu koji je prije otomanske vladavine u tom kraju pripadao Ninskoj biskupiji. Odlukom datiranom u Zadru 10. kolovoza 1670. dalmatinski providur Antonio Barbaro poklonio je posjed Jusuf-age Tunića u Islamu Grčkom Stojanu Mitroviću Jankoviću (oko 1635. - 1689.), Desničinu pretku. Premda je Stojan, kao povijesna ličnost, najpoznatiji kao protagonist narodne pjesme, susreće ga se i u jednom književno-umjetničkom i u više kritičkih radova. Međutim, dom predaka u Isla-

28 Istaknula S. R. Navodim prema, nažalost, nemarno uređenom, kasnijem izdanju: V. Desnica, Progutane polemike, Beograd 2001., 26. Francuski pisac Paul de Kock (1793. - 1871.) napisao je brojne romane koji su se često objavljivali u podlistku ondašnjih dnevnih novina, kao što je tršćanski Il Piccolo. Spominje ga Dostojevski u romanima Zli dusi i Braća Karamazovi.

29 Razgovor s Jeftom Milovićem, profesorom germanistike, vodio se u Zadru 31. kolovoza 1964. Usp. V. DesnicA, Hotimično iskustvo, 124. 
mu Grčkom nije zabilježen ni u jednom od njih; za vrijeme svoga ropstva Stojan nije živio na tom posjedu, a u lirskoj drami Janco, u kojoj je lik Janca oblikovan prema povijesnom predlošku Stojana Jankovića i koju je na talijanskom jeziku napisao Zadranin Giuseppe Ferrari-Cupilli, mjesto je radnje Jancov, odnosno Stojanov stan u Zadru, u Rajskoj ulici (calle del Paradiso), zato što se u to vrijeme Islam Grčki nalazio unutar turskih granica uspostavljenih linijom Nani iz $1671 .^{30}$

Sâm je Vladan Desnica rekao da je knjiga Proljeća Ivana Galeba „pisana, možemo reći i smišljana, dvadest i pet godina, tako da nema mjesta u kom sam živio a da nisam na njoj radio" " ${ }^{31}$ Pored kuće u Splitu iz autorova djetinjstva, Kula Jankovića, kako se dom u novije vrijeme označavao i označuje, nedvojbeno je prostorno i smisleno tijesno povezana s najpoznatijim Desničinim romanom. Ivan Basić, autor vrijedne monografije o povijesti Kule, iznosi tezu da bi „rascjepkanom prostoru u ladanjskoj građevini Islama Grčkog odgovaralo isto takvo, kloazonirano vrijeme u strukturi Desničina romana. U oba slučaja poveznica je tek proverbijalna 'tanka nit'."32

Dom kojemu je ne jednom u povijesti prijetio fizički nestanak ostao je trajno zapisan u nepotpisanim talijanskim stihovima visokog stilskog izraza Lento e misurato il rodere del tarlo, za koje mislim da se mogu atribuirati Vladanu Desnici. Premda je trideset godina kasnije, 1961., u jednom razgovoru izjavio da su stihovi za njega tek skica, polazna točka za daljnju razradu, odnosno „sasvim sporedna branša, da tako kažem, grana mog umjetničkog rada“",33 ova se pjesma može smatrati jednim od važnih temelja piščeve poetike u koju su nedvojbeno upletene niti romanske, a time i talijanske tradicije i kulture. Ili, sasvim sažeto: Desničina sretna metafora "godovi duše" u romanu Proljeća Ivana Galeba. Igre proljeća i smrti odnosi se na čovjekove proživljene godine, pri čemu su godovi imanentni slavenskoj tradiciji, ali s implicitnom aluzijom na italski način mjerenja čovjekova trajanja. ${ }^{34}$

30 Financijski savjetnik i dopisni član Arheološkog instituta u Rimu i Berlinu, Zadranin Giuseppe Ferrari-Cupilli (I809. - I865.), napisao je povijesnu dramu u tri čina na talijanskom jeziku Janko, posluživši se umjetničkom slobodom pri adaptaciji protagonistova imena, u kojoj tematizira tragični događaj iz lipnja 1676., kada je Stojan Janković, vrativši se u svoj dom u Zadru u Rajskoj ulici (Via del Paradiso), zatekao svoju ženu Vinku s kumom. Njega je ranio, a nju smaknuo trima udarcima sabljom. Dramu je posmrtno objavio Ferrari-Cupillijev sin Simone, bibliotekar u zadarskoj gradskoj biblioteci Paravia, u listu La Domenica (Zadar), br. 42, 20. 10. 1889., 460-462 (I. čin); br. 43, 27. 10. 1889., 473-474 (II. čin); br. 44, 3. 11. 1889., 484-485 (III. čin).

U svom radu „Bračna tragedija Stojana Jankovića“ (Srpski književni glasnik, 40/1940., knj. 61, 192-196) Boško Desnica na tragu Ferrari-Cupillijeva podatka navodi tragični događaj u Zadru što ga je zapisao Teodoro Rinaldi 1635. godine, no taj zapis ne nalazi u arhivima. U novije vrijeme objavljeni su i ovi filološki radovi: Sofia ZANI, „Stojan Janković u povijesti i legendi“, Riječ, 2/1996., br. 2, 170-180; Ana Bukvić, „Povijesno-kritički prikaz drame Janko Giuseppea Ferrari-Cupillija“, Ricerche slavistiche, 13/2015., br. 1, 265-282.

31 V. Desnica, Hotimično iskustvo, 121.

32 Ivan BAsić, Od domus episcopi do Kule Jankovića. Prostorni razvoj Kule Stojana Jankovića u Islamu Grčkom, Zagreb 2010., 56. O Kuli Jankovića usp. i mrežne stranice:

http://kula-jankovica.unizg.hr/hr/kula-jankovica/i http://www.kulajankovica.hr/kula-jankovica/jankovic-desnica/. Kuću u Splitu s plavim jabukama, kvakama na vratima Desnica spominje u razgovoru s Jeftom Milovićem, usp. V. Desnica, Hotimično iskustvo, 122.

33 Razgovor se 22. ožujka 1961. vodio s Nikolom Drenovcem na Radio Beogradu. Usp. V. Desnica, Hotimično iskustvo, 85.

34 Tako za izraz 'navršio je pedeset ljeta' Talijani kažu: ha compiuto cinquanta primavere, odnosno 'navršio je pedeset proljeća'.

Zahvaljujem profesorici Mariji Mitrović i profesoru Nenadu Iviću na čitanju i primjedbama ovome radu. 


\section{PRILOZI}

\section{A. Transkript pjesme Lento e misurato il rodere del tarlo}

Lento e misurato il rodere del tarlo, simbolo di lenta decomposizione, sento compier pigro l'opera di morte nel rudere sacro della mia magione.

Sotto il vecchio tetto fatal scorre il tempo, seguonsi le stirpi, s'avvicendan vite e coi giorni tristi, foschi e nubilosi la stagion dei fior s'alterna dolce e mite.

$\mathrm{O}$, mia vecchia casa quant'ardente fiamma spensero i tuoi muri umidi, ammuffiti, quant'impeti franser, sogni ed illusioni, quante nobil brame e conati arditi!

Genitrice d'alme generose e fiere, sembra che ciascun tuo nato e in te cresciuto obolo d'amore, sua più nobil parte, nel cammin terreno ti lasciò in tributo.

Dimmi i sogni e l'opre, l'ignorate angoscie dello spirto i spasmi, o magione avita, del pensier coi ceppi narrami le lotte e le dure prove e i stenti della vita.

Dalla secolare tradizion nudriti nella fe' degli avi, come in sacro fonte, ritemprati crebber gl'ultimi gentili tuoi con alma retta e con altera fronte. (1r)

Nel tuo grembo arrise tra infantili ludi lieta a noi la vita, roseo l'avvenire ma fia breve il sogno, e il disinganno rude farà atroce il dubbio e tardo il ripentire.

Dalla soglia antica nei giorni di sole van spiccando il volo giovinezze in fiore tratte dal miraggio di promesse liete col' desio nell'alma, colla fede in core,

Sull'antica soglia nell'orror del verno risuonar udrassi battito anelante sarà la vecchiezza, che infranta riede e ti chiede asil per l'alma dolorante. 
E mentre la vita compie il gioco atroce

di spietate beffe e di violenze amare

il presente scorre scolorato e grigio

tra timori folli e rimembranze care.

Tutto muta e fugge. Qual torrente irrompe

e tutto travolge l'epoca che incede

infrangendo quello che il passato eresse

per conforto all'alma e simbolo di fede.

Solo il tarlo ancora, pigro e misurato

compie l'opra sua di dissolvimento

simile al cronista, che gli eventi annota

gelido, imparziale, uniforme e lento. $(1 \mathrm{v})^{35}$

\section{B. Parafraza pjesme Polagano i uporno razaranje crva}

Polagano i postojano crv razara i uništava svetu ruševinu doma. Pod starim krovom smjenjuju se generacije i životi, smjenjuju se tužna, siva i oblačna doba s onim cvjetnim, dragim i nježnim.

O, kućo moja stara, koliko su živih plamenova ugasili tvoji vlažni i pljesnivi zidovi, prekinuli tolike strasti, snove i nade, tolike plemenite težnje i hrabre porive.

Roditeljice širokih i ponositih dušâ, čini se da ti je svaki onaj tko je u tebi rođen i odrastao vratio dug plemenitim djelovanjem na svom zemaljskom putu.

Ispričaj mi snove i djela, nepoznate strepnje duha i boli, o, dome predaka! Ispričaj mi borbe i teška iskušenja i životne teškoće!

Odgojeni u stoljetnoj tradiciji, poput krstionice, izrasli su hrabri tvoji posljednji izdanci uspravna duha i visoka čela.

U tvom nam je krilu uz djetinje igre život izgledao lijep, budućnost vedra, no bio je to samo san, a grubo osviještenje donijelo je gorku sumnju i kasno kajanje.

$S$ drevnoga praga za sunčanih dana polijeću rascvjetale mladosti privučene lijepim obećanjima s čežnjom u duši i vjerom u srcu.

Na drevnom pragu u strašnoj će se zimi začuti ponovljeno kucanje, bit će to starost koja se skrhana vraća i moli te da k sebi primiš bolnu dušu.

I dok život dovršava svoju surovu igru surovih šala i gorkog nasilja, sadašnjost protječe bezbojna i siva između ludih strahova i dragih sjećanja.

Sve se mijenja i prolazi. Poput bujice nahrupilo je novo doba rušeći ono što je prošlost sagradila za utjehu duši i kao simbol vjere.

Samo crv i dalje, lijen i postojan, dovršava svoje razaranje, sličan kroničaru koji bilježi događaje, leden, nepristran, jednoličan i spor.

35 Nekoliko manjih ortografskih propusta nalazi se u tekstu pjesme: u V. strofi, II. stih „i spasmi“ i u IV. stihu „i stenti“, ispravno je gli spasmi, gli stenti; u VI. strofi, II. stih: otisnuto je „fè “ umjesto fe' (elidirano fede); u VII. strofi, III. stih „fia“" umjesto $f u$, ili bolje era; u VIII. strofi, IV. stih unesen je suvišan apostrof tintom „col'“ umjesto col. Inače, original napisan pisaćim strojem sadrži veći broj ručno unesenih korekcija, većinom rukom Uroša Desnice. Vladan je unio ispravak u III. strofi, I. stihu: „quant”“. 


\section{Bibliografija radova Uroša Desnice na talijanskom jeziku. Sastavio Vladan Desnica. ${ }^{36}$}

U Osobnoj ostavštini Vladana Desnice, kutija Uroš Desnica II., nalazi se rukopisna „Bibliografija Dr. U. Desnice“, koju je sastavio Vladan Desnica. Nema nadnevka. Obuhvaća radove od 1898. do 1941. godine. Talijanskim su jezikom napisani:

1908.:

„I Serbo-Croati della Dalmazia, il loro atteggiamento dopo l'annessione della Bosnia-Erzegovina e i rapporti tra l'elemento Dalmata e il Croato", L'Italia all'Estero (Roma), br. 19, 5. 11. 1908., 173-178.

1909.:

„Ancora dell'annessione della Bosnia-Herzegovina“, L'Italia all'Estero (Roma), br. 3, 5. 2. 1909., 269-275.

1915.:

Grammatica russa (neobjavljeno), 677 stranica rukopisa

1919.:

„Lettere dal Zermagna“, Narodni list (Zadar), br. 8, 25. 2. 1919.; br. 9, 27. 2. 1919.; br. 13, 28. 3. 1919.; br. 11, 14. 3. 1919.; br. /?/, 7. 6. 1919. (potpis: Nemesio) ${ }^{37}$

1920.:

„Lettere dal Zermagna“, Narodni list (Zadar), br. 2, 29. 4. 1920.

„Leonida Bissolati“, Narodni list (Zadar), br. 3, 10. 5. 1920. (talijanski)

L'Umanità, 27. 5. 1920. (nepotpisan)

„Un messaggio“, Novo doba (Split), br. 255, 11. 11. 1920. (nepotpisan)

1922.:

„O. Randi: La Jugoslavia“, Novo doba (Split), br. 247, 26 /?/ 10. 1922. (talijanski)

1930.:

„La gesta di Castagnotto“, talijanska satirična pjesma (neobjavljeno)

36 Dopuna su ovoj bibliografiji još dva rada koja je u obiteljskom arhivu Desnica pronašao profesor Drago Roksandić. Prvi je prijevod na talijanski jezik 32 stiha Posvete Goetheova Fausta u dvjema verzijama: rukopisnoj, u kojoj je rukom Vladana Desnice dodano: „Preveo Dr Uroš Desnica, u Splitu, 2/6/36“, a kasnije je istom rukom dodano: „2-VI1936." i u prijepisu strojopisom s istim datumom. Drugi je rad pismo u stihovima na zadarskom dijalektu, sastavljeno od deset kvartina rimovanih prema shemi abab. Sastavak je datiran: „Obrovazzo 6/4 1925“ i potpisan „Uroš“, a upućen je bliskom prijatelju Jovi Marčetiću u Zagreb. Primatelj odgovara vijencem od jedanaest soneta, također na zadarskom dijalektu te na kraju pozdravlja Fanny i „malene“ te navodi datum in extenso, 11. travnja 1925.

U natuknici Hrvatskog biografskog leksikona koju je sastavila Marita Batinović navodi se da je Uroš Desnica surađivao i u talijanskim listovima Il Lavoratore i L'Umanità.

37 Potpunu kronologiju pisama usp. u bilješci 3 ovog rada. 


\section{$\cos$}

\section{The anCestral home in Islam GrČKi as a POETIC MOTIF: AN UNKNOWN POEM IN ITALIAN FROM THE DESNICA}

\section{FAMILY ARCHIVE}

Since the Venetian rule in Dalmatia, elements of Croatian, Serbian and Italian cultures have intertwined. The use of Italian language and culture was inherent not only to ethnic Italians populating the area, but to their educated neighbours of Slavic origin as well. This is the light in which intercultural relations in the area should be observed up until the end of World War II, when most ethnic Italians left Dalmatia and Istria. Still, cultural intertwining remained a fixture in the lives of those individuals of Italian descent who remained in the area after the war, as in the work of Croatian and Serbian scholars specializing in history, Italian culture or comparative literature. In this paper, I analyze a previously unknown document from the archive of the Desnica family, kindly given to me by Professor Roksandić, in that context. It is a typewritten copy of the poem Lento $e$ misurato il rodere del tarlo, which was mailed by Uroš Desnica from Split to his son's Zagreb address in 1931. A detailed analysis of the metre and content of the poem invited a conclusion that the author of this poem, written in Italian, was the young Vladan Desnica himself, while his father Uroš contributed to its translation into Italian, or its editing. This previously unknown work testifies to Vladan Desnica's development as a young intellectual and future writer, one whose work would provide synthesis, at the highest level, of the impulses from the aforementioned three cultures.

Key words: Croatian, Serbian and Italian cultural intertwining in Dalmatia, an unknown poem in Italian, the work of Vladan Desnica, the work of Uroš Desnica

\section{$\cos$}

\section{Izvori}

La Domenica (Zadar), 1889.

Narodni list (Il Nazionale) (Zadar), 1919. - 1920.

\section{Literatura}

Ivan Basić, Od domus episcopi do Kule Jankovića. Prostorni razvoj Kule Stojana Jankovića u Islamu Grčkom, Zagreb 2010.

Ana Bukvić, „Povijesno-kritički prikaz drame Janko Giuseppea Ferrari-Cupillija“, Ricerche slavistiche, 13/2015., br. 1, 265-282.

Giosue Carducci, Rime nuove (1867., 1872.), u: Letteratura Italiana Einaudi, pretisak iz Edizione Nazionale delle Opere, Bologna 1942.

Boško DesnicA, „Bračna tragedija Stojana Jankovića“, Srpski književni glasnik, 40/1940., knj. 61, 192-196.

Vladan Desnica, Hotimično iskustvo, knj. 2., Zagreb 2006.

Vladan Desnica, Progutane polemike, Beograd 2001. 
Vladan Desnica, Proljeća Ivana Galeba. Igre proljeća i smrti, Zagreb 1975.

Vladan Desnica, Zimsko ljetovanje. Pjesme. Ljestve Jakovljeve, Zagreb 1974.

Željko ĐurIĆ, Srpsko-italijanske književne i kulturne veze od XVIII do XX veka, Beograd 2012.

Leksikon antičkih autora (prir. Dubravko Škiljan), Zagreb 1996.

Dimitrije MašAnović, „Dva susreta s Vladanom Desnicom“, Književne novine, 19/1967., br. 297, 1 i 12 .

Kosta Milutinović, „Od Stojana Jankovića do Vladana Desnice“, Zadarska revija, 18/1968., 9-37.

Francesco Petrarca, Il Canzoniere / Kanconijer (ur. Frano Čale), Zagreb - Dubrovnik 1974.

Dušan Puvačić, „Priča o izgubljenom rukopisu (Trideset šest pisama Vladana Desnice E. D. Goju“, Letopis Matice srpske, 172/1996., knj. 458, sv. 6, 329.

Sanja RoIć, Stranci. Portreti s granice, margine i periferije, Zagreb 2006.

Paul Valéry, Il Cimitero marino (ur. Maria Teresa Giaveri), Milano 1984.

Sofia ZANI, „Stojan Janković u povijesti i legendi“, Riječ, 2/1996., br. 2, 170-180.

\section{Mrežne stranice}

„Prigioneri austroungarici a Gualdo Tadino“

(http://www.gualdograndeguerra.com/index.php/prigionieri-e-internati-a-gualdo-tadino)

„O Kuli Jankovića“

(http://kula-jankovica.unizg.hr/hr/kula-jankovica/)

(http://kulajankovica.hr/kula-jankovica/jankovic-desnica/) 